\title{
Actual Delivered Density Fire Test Apparatus for Sprinklers Protecting High Commodity Storage
}

\author{
JOHN A. SCHWILLE, HSIANG-CHENG KUNG, MARIA HJOHLMAN, \\ GEORGE E. LAVERICK and GARY W. GARDELL \\ Underwriters Laboratories Inc. \\ 333 Pfingsten Road \\ Northbrook, IL 60062, USA
}

\begin{abstract}
Due to increasing challenges in protecting high commodity storage, sprinkler designers need improved predictive tools. Actual Delivered Density (ADD) fire test data can be used to screen automatic sprinkler designs. An improved ADD fire test apparatus was developed at Underwriters Laboratories for use in developing new sprinklers for protecting high storage facilities. This paper presents the development of the apparatus and initial measurements. Calibration of the fire plume of the ADD apparatus to measurements in four tier rack storage fires indicate that fire plume temperatures and velocities are generally within $10 \%$ of those measured in specific rack storage fires. Measured ADD values typically increase with higher sprinkler flow rates, although some sprinkler designs and ignition locations show diminishing returns.
\end{abstract}

KEYWORDS: Actual Delivered Density (ADD), fire sprinkler, water spray

\section{NOMENCLATURE LISTING}

$Z$

$r_{t}$

$r_{V}$

$Q_{w} \quad$ sprinkler flow rate $(\mathrm{L} / \mathrm{min})$

$A D D$

$\Delta T_{c}$

plume temperature measurement radius (m)

$r_{v} \quad$ plume velocity measurement radius $(\mathrm{m})$
Actual Delivered Density

$\left(\mathrm{L} / \mathrm{min} / \mathrm{m}^{2}\right)$

plume centerline

temperature difference from

ambient temperature $\left({ }^{\circ} \mathrm{C}\right)$

plume off center

temperature difference from

ambient temperature $\left({ }^{\circ} \mathrm{C}\right)$

plume centerline vertical

velocity $(\mathrm{m} / \mathrm{s})$

\section{INTRODUCTION}

With a steady increase in commodity storage heights, automatic sprinkler designers have been challenged to develop new fire sprinklers to protect storage facilities, while at the same time incurring more difficulty in demonstrating acceptable results in higher storage arrays. Among the three common storage arrangements: rack, palletized, and solid-pile storages, rack storage has been recognized as the most challenging toward sprinkler protection. Rack storage arrangements favor rapid and intense fire growth because combustible surfaces extend both vertically between storage units placed back-to-back and side-to-side and horizontally between storage units on different levels. Once initiated, fires spread through both vertical flues and along horizontal channels, rapidly growing faster and becoming more intense. To offset this increase in the fire protection challenge, new predictive tools have been developed. Several major research activities have been devoted to understanding sprinkler performance in rack storage fires in the past two 
decades $[1,2,3,4]$. These research programs have aided in the development of Early Suppression Fast Response (ESFR) Sprinklers [5,6,7].

In the ESFR Sprinkler Research Program, the concept of the Actual Delivered Density (ADD) of sprinklers in rack-storage fires was introduced [8]. The ADD is the water flux delivered to the top surface of a burning rack-storage array after penetrating through the fire plume. An experimental apparatus was designed and built in the mid-1980s to measure ADD of ESFR prototype sprinklers [8]. The first generation ADD apparatus consisted of a 2x2 array of four simulated commodities and a fire source. The simulated commodity was made of steel plates having a dimension of $1.07 \mathrm{~m}$ by $1.07 \mathrm{~m}$ by $1.07 \mathrm{~m}$. The top of each simulated commodity consisted of four water collection pans. A $0.15 \mathrm{~m}$ wide flue was maintained between two adjacent commodities. The fire source was placed beneath the simulated commodities and consisted of eight commercially available fuel nozzles that use heptane as fuel. The heat losses of the heptane spray fire to the steel boxes (simulated commodities) were not known. The temperatures and velocities of the fire plume generated by the apparatus were not known, which should closely match certain rack storage fire plumes.

A second generation of the ADD test apparatus was designed and constructed by Chan et al. [4] in the early 1990s. The second generation ADD apparatus consisted of an array of water collection pans and a fire source. The area covered by the collection pans simulated the entire top surface of a two-pallet-load deep by four-pallet-load wide double-row rack storage array [4,9]. However, there were no flue spaces between the collection pans. The fire source was generated from nine commercially-available fuel nozzles that used heptane as fuel. All nine fuel nozzles were placed $0.152 \mathrm{~m}$ above the water collection pans. Eight nozzles were equally spaced on a 1.22-m diameter circle and one nozzle was located at the center of the circle. Only a 0.203-m diameter opening was provided at the center of the apparatus to supply duct air at a flow rate of $307 \mathrm{~L} / \mathrm{s}$. The nozzle arrangements and heptane supply pressures used by the ADD apparatus to achieve the five different convective heat release rates of the fire plumes are presented in Table 1 of Reference 4 . Table 2 in Reference 4 shows the gas velocities and temperatures of fire plumes generated by the apparatus in comparison with data measured from fire plumes of a 6.1-m high rack storage fire of the Standard Class II Commodity [1].

The fire plume characteristics (velocity and temperature) close to the top surface of the rack storage were strongly influenced by the gas flow rising through the flue spaces. However, this version of ADD apparatus provided no flue spaces. All the air entrained into the plume flowed radially from the ambient atmosphere above the top surface of the collection pans, except the forced duct air supply through the $0.203-\mathrm{m}$ diameter opening. As indicated in Table 2 of Ref. 4, the gas temperature measurements of the ADD fire plume at an elevation of $1.04 \mathrm{~m}$ above the top surface of the fuel array were significantly higher than those of the rack storage fire plume. The near field of the fire plume (located close to the top surface of the fuel array) generated by the ADD apparatus was not simulated closely to actual fires. In the measurements of ADD, the near field of the fire plume was expected to have a significant effect on the measured values.

With the increasing storage heights of commodities, the accurate representation of the fires seen in large storage arrays is of key importance. This paper presents a third generation of the ADD test apparatus, which simulates accurately both the near field and far field of the rack storage fire plume. The ADD apparatus focuses on a collection area, simulating a multiple-row rack arrangement rather than a double-row arrangement, and the generation of a plume that is similar to fire plumes from a rack storage arrangement 
of a standard test commodity. This rack storage arrangement has been frequently used in the standard test fires for sprinkler development work. Therefore, we expect to use the new ADD apparatus as a screening tool for new sprinkler designs before we subject them to large-scale fire tests. Also, the ADD measurements may be used to predict sprinkler suppression performance in large-scale fire tests. Therefore, the number of large-scale fire tests required for evaluating sprinkler performance may be reduced. For simulating other storage fires of specific commodities, the design concept and calibration procedure of the ADD apparatus developed in this paper can be applied. Using this third generation apparatus, ADD measurements of a Large Drop sprinkler and an ESFR upright sprinkler have been performed. The effects of water discharge rate, ceiling clearance, and fire source location on ADD have been investigated.

\section{TEST APPARATUS}

The new ADD apparatus also consists of a fire source and a set of water collection pans. A drawing of the top and side views of the apparatus is shown in Fig. 1. The main components of the apparatus are 48 water collection pans and 12 heptane nozzles. The 48 water collection pans are $0.5 \mathrm{~m}$ x $0.5 \mathrm{~m}$ and are separated into groups of four. A group of four collection pans, i.e., a 2x2 array, simulates the top surface of one pallet load of stored commodity. Eight groups of four are placed in the main array, while two satellite arrays each consist of two groups of four. The two satellite collector arrays can be placed adjacent to the main array to investigate pre-wetting of sprinkler spray on a multiple-row storage array. A $0.15-\mathrm{m}$ flue space is maintained between two adjacent simulated commodities. The complete ADD apparatus simulates a $4 \mathrm{x} 4$ array of stored pallet loads of commodity except no commodity is simulated in the corners of the array.

The fire source is intended to simulate the fire plume of 6.1-m high rack storage arrangement of Standard Class II Commodity. In order to accurately simulate both the near field and far field of the rack storage fire plume, flue spaces are provided between the simulated commodities. The fire plume is generated from an array of twelve heptane nozzles supplied with heptane. The nozzles are placed in the flue spaces located near the center of the test array as shown in Fig. 1. All twelve nozzles are located $30 \mathrm{~mm}$ beneath the top surface of the collection pans. Air is entrained into the spray fires through the flue spaces. Additional unheated air is provided at $250 \mathrm{~L} / \mathrm{s}$ by a $20.3 \mathrm{~cm}$ diameter duct at the center of the apparatus.

Each individual collection pan uses an inverted pyramid to funnel the collected sprinkler water to a $5.1 \mathrm{~cm}$ diameter tube that leads to a large $45.7 \mathrm{~cm}$ diameter container. The containers, which are covered to prevent contamination, have a pressure tap located $1.3 \mathrm{~cm}$ above the bottom. The measured pressure is used to calculate the amount of water in the containers, and thus the amount of water delivered through the fire plume to the collection pans. The undersides of all the water collection pans are cooled by water spray nozzles to keep the pan temperatures from significantly increasing due to flame radiation.

The fire and its plume are created by 12 heptane nozzles situated in the $15.2 \mathrm{~cm}$ flues between the water collection pans of the main array, as shown in Fig. 1. Heptane is delivered to these nozzles through a 13-mm diameter manifold with copper tubings. The nozzles are spaced at three radial distances from the center of the array and are angled towards the center of the array. The distances of the nozzles and angles were adjusted during the calibration of the apparatus and are summarized in Table 1. The placement of these nozzles is one of the improvements in this third generation ADD apparatus 
compared to previous ADD apparatus. Placing the heptane nozzles in the flue spaces between the water collection pans is a more accurate re-creation of a rack storage fire where the majority of the combustion occurs in the flue spaces below the surface of the commodity.

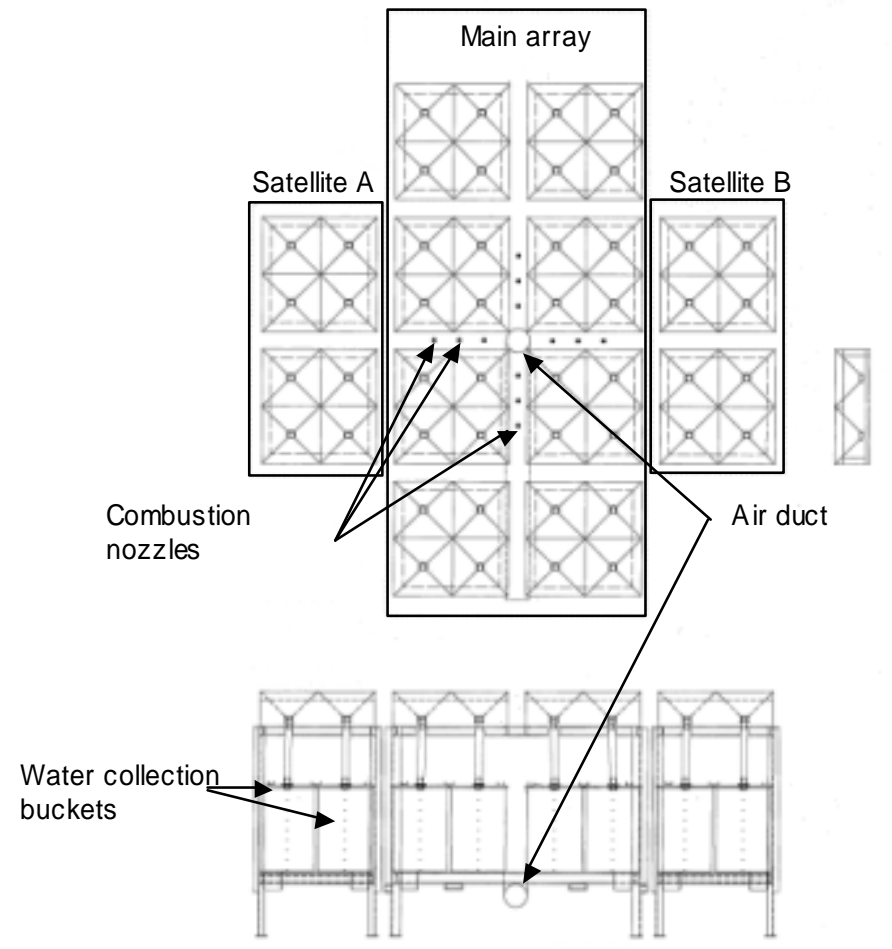

Fig. 1. A schematic of the Actual Delivered Density Apparatus.

One of the key aspects of the ADD apparatus is to be able to accurately simulate different size fires (in terms of convective heat release rates). Not only does the overall heat release rate of a fire change with size, but the area of combustion also increases in larger size fires. In order to control the distribution of heat release rate in the ADD apparatus, different size heptane nozzles are used for different size fires. For example, for the smallest size fire that is addressed in the calibration section $(500 \mathrm{~kW})$, the heptane nozzles close to the center are the same size as the nozzles at the further radial distances. For the larger fire sizes, the capacity of the nozzles at the furthest radial distance is large compared to the center nozzles. This spreads more combustion throughout the flue spaces, representing the radial extent of a large fire. Changing nozzle capacity according to fire size also keeps the differential pressure across the nozzle orifice above $310 \mathrm{kPa}$ to ensure good atomization and combustion efficiency. Table 1 summarizes the nozzles used for each fire and the nozzle angles with respect to the horizontal plane. The heptane discharge rates for the five convective heat release rates used in this study are the same as those used by Chan et al. [4]. 
Table 1. Heptane nozzle configurations.

\begin{tabular}{|r|r|r|r|r|r|r|r|r|r|r|}
\hline & & \multicolumn{3}{|c|}{ Inner Nozzle } & \multicolumn{3}{|c|}{ Middle Nozzle } & \multicolumn{3}{c|}{ Outer Nozzle } \\
\hline $\begin{array}{l}\text { Fire } \\
\text { Size }\end{array}$ & $\begin{array}{c}\text { Heptane } \\
\text { Flow }\end{array}$ & Radius & Angle & Capacity & Radius & Angle & Capacity & Radius & Angle & Capacity \\
\hline$(\mathrm{kW})$ & $(\mathrm{Lph})$ & $(\mathrm{m})$ & $(\mathrm{deg})$ & $(\mathrm{Lph})$ & $(\mathrm{m})$ & $(\mathrm{deg})$ & $(\mathrm{Lph})$ & $(\mathrm{m})$ & $(\mathrm{deg})$ & $(\mathrm{Lph})$ \\
\hline 500 & 1.5 & 0.11 & 75 & 11.4 & 0.36 & 75 & 11.4 & 0.81 & 60 & 11.4 \\
\hline 1000 & 3.1 & 0.11 & 75 & 20.8 & 0.36 & 75 & 11.4 & 0.81 & 60 & 34.0 \\
\hline 1500 & 4.6 & 0.11 & 75 & 30.4 & 0.36 & 75 & 11.4 & 0.81 & 60 & 45.4 \\
\hline 2000 & 6.5 & 0.11 & 75 & 45.4 & 0.36 & 75 & 11.4 & 0.81 & 60 & 71.9 \\
\hline 2500 & 8.1 & 0.11 & 75 & 45.4 & 0.36 & 75 & 11.4 & 0.81 & 60 & 71.9 \\
\hline
\end{tabular}

All the tests were conducted in the UL large-scale fire test facility located in Northbrook, Illinois. Overall interior dimensions of the test building are $36.6 \mathrm{~m}$ x $36.6 \mathrm{~m}$ x $16.5 \mathrm{~m}$ high. A $30.5 \mathrm{~m} 30.5 \mathrm{~m}$ height-adjustable ceiling is located in the center of the building, with $3.05 \mathrm{~m}$ gaps between the ceiling and the interior walls. The ceiling can be raised or lowered to provide floor-to-ceiling distances from $3.05 \mathrm{~m}$ to $14.6 \mathrm{~m}$. The sprinklers were installed on pipes of nominal 7.62-cm diameter under the ceiling via welded outlets (with $2.5 \mathrm{~cm}$ to $1.9 \mathrm{~cm}$ bushings). The centerlines of the sprinkler pipes were $0.318 \mathrm{~m}$ below the ceiling. The two deflector-supporting arms of each sprinkler were aligned with the sprinkler pipe. The sprinkler spacing was maintained at $3.05 \mathrm{~m}$ by $3.05 \mathrm{~m}$.

Combustion gases were exhausted from two $4.3 \mathrm{~m}$ x $9.1 \mathrm{~m}$ x $0.3 \mathrm{~m}$ plenums at the top of the roof connected to a smoke abatement system. The exhaust rate was set at $17 \mathrm{~m}^{3} / \mathrm{s}$ of air at room temperature. Fresh air was supplied via four 1.1-m diameter ducts, close to the corners of the room, with the openings located $4.3 \mathrm{~m}$ above the floor, facing downward. For tests without fire, the exhaust blower was shut off.

\section{CALIBRATION}

In order to use the ADD apparatus to evaluate new sprinkler designs or validate fire models, the flame and plume produced by the heptane nozzles must be comparable to that produced by actual commodity. Previous ADD apparatus have been calibrated against fire plume temperatures and velocities measured in fires from a 2 by 2 by 4 ( 4 tiers) rack storage arrangement of the Standard Class II Commodity [1]. The ADD apparatus presented here also used the same fire data published from that testing as a baseline for calibration.

Both centerline and off-center data were used to ensure the fire plumes represented plumes observed in commodity rack storage fires. Temperature and velocity data at three heights from the plane of the collection pans were obtained for a period of five minutes. The location of measurements is shown schematically in Fig. 2. Overall, five fire sizes were used to calibrate the new ADD apparatus. While the energy output of the device's combustion nozzles was determined by regulating the heptane flow rate through the nozzles, the distribution of the plume could be adjusted by nozzle position, nozzle orientation and duct air flow rate. 


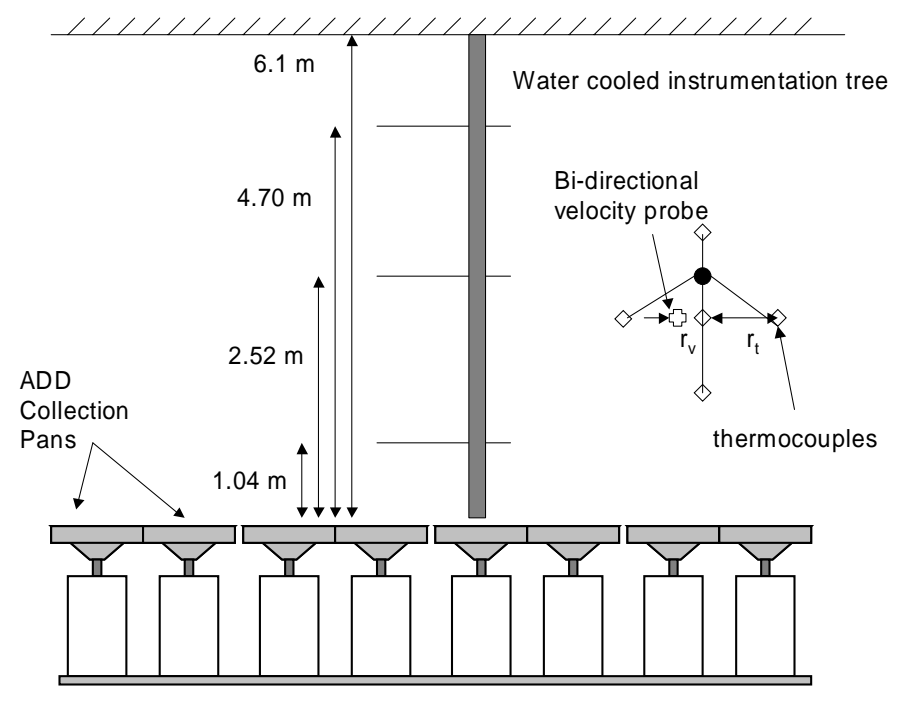

Fig. 2. Temperature and velocity measurement locations for calibration. Thermocouple measurements taken at radius $r_{t}=0.406 \mathrm{~m}$ at $z=1.04 \mathrm{~m}$ and $\mathrm{z}=2.56 \mathrm{~m}, r_{t}=0.457 \mathrm{~m}$ at $\mathrm{z}=6.1$. Velocity probe measurements taken at $r_{v}=0.05 \mathrm{~m}$ at all heights.

A comparison between the measured centerline temperature, $\Delta T_{c}$, the average of four offcenter temperatures, $\Delta T_{o}$, and the centerline velocity, $u_{c}$, from a physical rack storage fire, the new ADD apparatus and a previous apparatus is shown in Table 2. Except for the smallest fire size, the values shown are averages from two or three tests with identical nozzle configurations. Repeatability was excellent, with temperatures being within $10 \%$ of the average value and velocities being within $5 \%$.

The fire plume produced by the combustion nozzles of the new ADD apparatus is very similar to plumes encountered in fires involving rack storage of commodity, as shown by the comparison presented in Table 2. In the near field at 1.04-m elevation from the top surface of the collection pans, the centerline temperatures generated by the new ADD apparatus are very close to the measured fire-test centerline temperatures (within 11\%) for the $500 \mathrm{~kW}, 2000 \mathrm{~kW}$ and $2500 \mathrm{~kW}$ fires. For the $1000 \mathrm{~kW}$ fire at $1.04-\mathrm{m}$ elevation, the new ADD apparatus generates approximately the same centerline temperature as the previous ADD apparatus and considerably lower than the fire-test temperature. For the $1500 \mathrm{~kW}$ fire at 1.04-m elevation, the previous ADD apparatus generates centerline temperatures closer to the fire-test temperature than that of the ADD apparatus. Overall, the centerline temperatures at the three elevations of the new ADD apparatus tend to be slightly higher, averaging 9\% higher than the measured fire-test centerline temperatures. Also, centerline velocities at all the three elevations of the new apparatus are very close to those of the commodity storage fire test, as shown by the data in Table 2 . 
Table 2. Comparison of the New ADD apparatus with fire data and previous ADD apparatus.

\begin{tabular}{|c|c|c|c|c|c|c|c|c|c|}
\hline & \multicolumn{3}{|c|}{$1.04 \mathrm{~m}$} & \multicolumn{3}{|c|}{$2.56 \mathrm{~m}$} & \multicolumn{3}{|c|}{$4.70 \mathrm{~m}$} \\
\hline & $\Delta \mathbf{T}_{\mathrm{c}}$ & $\Delta \mathbf{T}_{\mathbf{O}}$ & $\mathbf{u}_{\mathbf{c}}$ & $\Delta \mathbf{T}_{\mathrm{c}}$ & $\Delta \mathbf{T}_{\mathbf{O}}$ & $\mathbf{u}_{\mathbf{c}}$ & $\Delta \mathbf{T}_{\mathrm{c}}$ & $\Delta \mathbf{T}_{\mathrm{O}}$ & $\mathbf{u}_{\mathbf{c}}$ \\
\hline $500 \mathrm{~kW} \mathrm{~F}$ & & & & & & & & & \\
\hline Fire Test & 330 & 207 & 7.3 & 162 & 104 & 6.5 & 94 & 54 & 6.2 \\
\hline ADD & 302 & 287 & 6.7 & 241 & 115 & 7.0 & 128 & 67 & 6.1 \\
\hline Previous & 182 & 466 & 7.6 & 181 & 145 & 6.7 & 112 & 82 & 5.9 \\
\hline $1000 \mathrm{~kW}$ & & & & & & & & & \\
\hline Fire Test & 675 & 415 & 9.6 & 331 & 198 & NA & 162 & 103 & 7.6 \\
\hline ADD & 441 & 399 & 10.0 & 360 & 199 & 9.0 & 199 & 123 & 7.0 \\
\hline Previous & 421 & 875 & 9.1 & 376 & 284 & 8.9 & 203 & 152 & 7.5 \\
\hline $1500 \mathrm{~kW}$ & & & & & & & & & \\
\hline Fire Test & 846 & 524 & 10.5 & 524 & 300 & 9.5 & 253 & 156 & 9.1 \\
\hline ADD & 639 & 687 & 11.0 & 570 & 339 & 11.0 & 322 & 196 & 9.0 \\
\hline Previous & 792 & 1012 & 10.4 & 556 & 380 & 10.1 & 274 & 208 & 9.1 \\
\hline $2000 \mathrm{~kW}$ & & & & & & & & & \\
\hline Fire Test & 891 & 656 & 10.7 & 760 & 333 & 11.0 & 355 & 207 & 10.7 \\
\hline ADD & 786 & 803 & 11.4 & 731 & 474 & 11.8 & 424 & 259 & 10.3 \\
\hline Previous & 896 & 1048 & 10.5 & 760 & 533 & 11.8 & 373 & 275 & 9.9 \\
\hline $2500 \mathrm{~kW}$ & & & & & & & & & \\
\hline Fire Test & 915 & 692 & 10.8 & 810 & 468 & 9.1 & 408 & 245 & 11.0 \\
\hline ADD & 1011 & 879 & 11.0 & 854 & 578 & 12.0 & 506 & 309 & 11.0 \\
\hline Previous & 889 & 1121 & 10.8 & 846 & 671 & 12.5 & 472 & 318 & 10.5 \\
\hline
\end{tabular}

The previous ADD apparatus provided no flue spaces and all the fuel nozzles were placed $0.152 \mathrm{~m}$ above the water collection pans; it has only adequately produced fire plumes similar to the far field of the plumes found in commodity storage fire tests. For the new ADD apparatus, flue spaces are provided among the water collection pans; fuel nozzles are placed in the flue spaces; and air is entrained through the flue spaces to heptane sprays. The new apparatus is a significant improvement in simulating both the far field and near field of rack storage fire plumes. This is demonstrated by the off-centerline temperatures measured at $1.04-\mathrm{m}$ elevation. For example, the temperatures at a radius of $r=40.6 \mathrm{~cm}$ and a height of $z=1.04 \mathrm{~m}$ have an average deviation of $22 \%$ from the rack storage plume, while the previous apparatus averages a deviation of $57 \%$ from the rack storage plume. In some cases, the temperatures of the previous ADD apparatus are double of those present in the plume from the Class II commodity.

\section{MEASUREMENTS}

The ADD apparatus provides a valuable screening tool in sprinkler design development when data from previously successful fire sprinklers are used for comparison. To provide this, a series of tests was performed with three sprinkler designs. Two of the designs, designated as Sprinkler A and Sprinkler B, were large drop sprinkler designs with nominal K factors of $161 \mathrm{Lpm} / \mathrm{bar}^{1 / 2}$ (K161) from two different manufacturers. ESFR sprinklers have significantly different distribution patterns than other sprinklers, so an 
upright ESFR sprinkler with a nominal K factor of $202 \mathrm{Lpm} / \mathrm{bar}^{1 / 2}$ (Sprinkler C) was also tested.

Before each test, water was discharged through the open sprinkler(s) and the pressure was adjusted to the designated value using a flow control system. The water flow to the sprinkler(s) was then shut off. The heptane spray was then ignited and allowed to burn for 30 seconds before actuation of the pneumatic valves to start the sprinkler water flow.

The ADD is defined as the average water density (flux) over the area of the center 16 collection pans; the area covered by these pans corresponds to the top surface of the ignition array ( 2 pallet loads by 2 pallet loads) in a large-scale rack storage fire test. The ADD for one K161 large drop sprinkler located directly above a $2000 \mathrm{~kW}$ fire is shown in Fig. 3. The ADD increased as the sprinkler discharge rate increased from $210 \mathrm{~L} / \mathrm{min}$ to $300 \mathrm{~L} / \mathrm{min}$. However, it appears that increasing water flow through the sprinkler beyond $300 \mathrm{~L} / \mathrm{min}$ does not cause the measured ADD values to increase. This is likely due to the decrease in drop size that comes with more flow through a given orifice size [10]. Also, the measured ADD values are observed to decrease with higher ceiling clearance. It is interesting to note that the two different sprinklers deliver relatively similar ADD values at $\mathrm{Q}_{\mathrm{w}}=210$ and $370 \mathrm{~L} / \mathrm{min}$ but not at $300 \mathrm{~L} / \mathrm{min}$. In addition, at a clearance of $4.57 \mathrm{~m}$, the ADD for sprinkler $A$ is higher than the ADD for sprinkler $B$ at $Q_{w}=210 \mathrm{~L} / \mathrm{min}$, but the reverse is true for $\mathrm{Q}_{\mathrm{w}}=210$ and $370 \mathrm{~L} / \mathrm{min}$. These variations between the ADD of the two sprinklers at certain flow rates may also be a result of different spray patterns and drop sizes created by the two sprinklers.

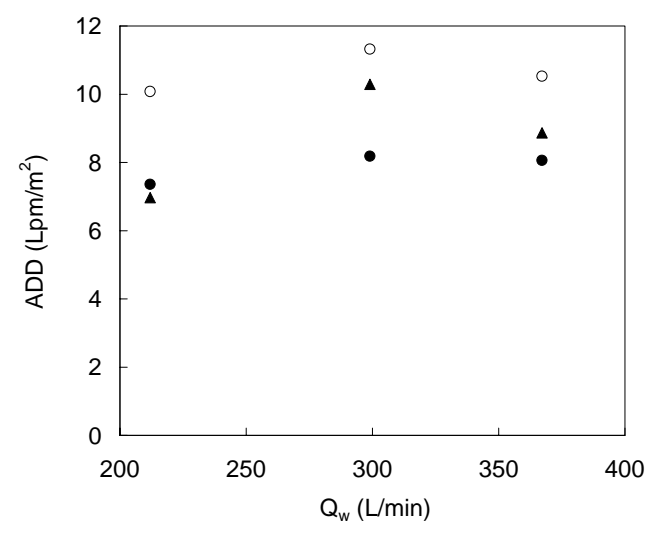

Fig. 3. The ADD from one K161 large drop sprinkler with $2000 \mathrm{~kW}$ fire directly underneath (O: Sprinkler A, 3.05 m clearance, O: Sprinkler A, 4.57 m clearance, $\mathbf{\Delta}$ : Sprinkler B, 4.57 m clearance.)

It is important to investigate sprinkler performance for ignition locations other than directly underneath the sprinkler. Figure 4 shows the ADD from four of the large drop sprinklers with a $2000 \mathrm{~kW}$ fire centered between the four sprinklers. Again, there is the clear and expected trend showing that as the water flow rate through the sprinkler increases, the actual delivered density increases. However, in comparison to the ADD from sprinklers located directly above the fire, the ADD continues to increase at the higher flow rates for this ignition scenario. When the fire sprinkler is located directly above the fire, the downward transit of the spray droplets is directly opposed by the upward velocity of the plume. This results in high drag force on the droplets from the fire 
plume and a longer time of exposure to the plume's upward velocity and high temperature. In contrast, when the ignition location is away from the centerline of the sprinkler, the droplets may enter the plume at a lower elevation and thus face a shorter transit distance to reach the fire. In addition, larger droplets with higher momentum are more likely to travel the longer distance from the sprinkler centerline to reach the ignition between four sprinklers. These larger droplets are not as affected by the fire as the smaller droplets underneath one sprinkler. This effect is dependent on sprinkler design.

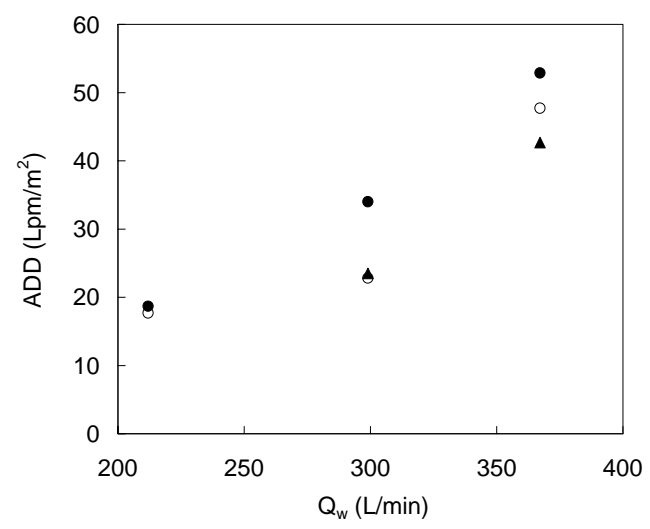

Fig. 4. The ADD from four K161 large drop sprinklers with $2000 \mathrm{~kW}$ fire between the 4 (O: Sprinkler A, $3.05 \mathrm{~m}$ clearance, O: Sprinkler A, $4.57 \mathrm{~m}$ clearance, $\mathbf{\Delta}$ : Sprinkler B, 4.57 m clearance.)

The large drop sprinklers are designed to project substantial quantity of large droplets to the perimeter of their umbrella spray patterns. For the scenario with the fire centered below four large-drop sprinklers, as the ceiling clearance increased from $3.05 \mathrm{~m}$ to $4.57 \mathrm{~m}$, the overlapping of the sprays increased, and the ADD also increased.

The influence of sprinkler design can be examined by measuring the ADD of a sprinkler with a different fire control or suppression strategy than the large drop sprinklers. Figure 5 shows the ADD from an ESFR upright sprinkler with a nominal discharge coefficient of $202 \mathrm{Lpm} / \mathrm{bar}^{1 / 2}$ (K202). These sprinklers are designed to suppress the fire plume, especially underneath a single sprinkler. Clearly, an ESFR sprinkler does not suffer the same diminishing delivered density at higher sprinkler flow rates as compared to the large drop sprinklers. As the flow rate through the sprinkler increases, the ADD increases at almost a linear rate.

The penetration ratio of a sprinkler spray is defined as the ratio of the ADD with fire versus the ADD without fire. For the K202 ESFR sprinkler spray directly above the 1000 $\mathrm{kW}$ fire, the penetration ratio ranges from 0.50 to 0.88 . The data indicates that the presence of the fire has a small effect on the ADD for the K202 ESFR sprinkler. While counter-intuitive, this effect is due to the suppression strategy employed by these sprinklers. By pushing the plume downward toward the fire origin, the spray from ESFR sprinklers encounters less of the high temperature upward moving air that would decrease the amount of water delivered to the measurement plane. For the sprinkler spray directly over the fire, ADD decreases as ceiling clearance increases, as shown in Fig. 5. 


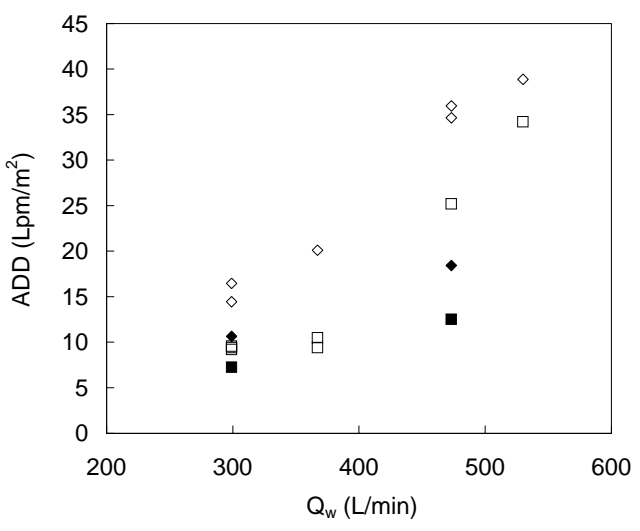

Fig. 5. Comparison of the ADD from -one K202 ESFR sprinkler (Sprinkler C) directly above a $1000 \mathrm{~kW}$ fire and no fire. ( $\square: 1000 \mathrm{~kW}$ fire and $3.05 \mathrm{~m}$ clearance,

口: $1000 \mathrm{~kW}$ fire and $4.57 \mathrm{~m}$ clearance, $\diamond$ : No fire and $3.05 \mathrm{~m}$ clearance,

$\diamond$ : No fire and $4.57 \mathrm{~m}$ clearance.)

\section{CONCLUSION}

A third generation ADD test apparatus has been constructed with the objective of improving the correlation between screening tests and large-scale rack storage fires. By placing the heptane combustion nozzles in the flue spaces, the reaction zone of the fire is closer to the region where it occurs in commodity fires. The temperature and velocities in the plume by the apparatus closely match the temperature and velocities in fires involving actual commodity.

Baseline measurements have been made that can provide sprinkler designers with useful comparison points. Although ADD is not a sole predictor of sprinkler performance in rack storage fire, it can provide more confidence that a prototype sprinkler will suppress fires involving multiple tiers of actual commodity.

\section{ACKNOWLEDGEMENTS}

The authors acknowledge the valuable support and comments of Dr. J. Thomas Chapin, Dr. Pravinary D. Gandhi, and Mr. Kerry M. Bell.

\section{REFERENCES}

[1] You, H.Z. and Kung, H.C., "Strong Buoyant Plumes of Growing Rack Storage Fires,” Twentieth Symposium (International) on Combustion, The Combustion Institute, 1984, pp. 1547-1555.

[2] Kung, H.C., You, H.Z., and Spaulding "Ceiling Flows of Growing Rack Storage Fires,” Twenty-first Symposium (International) on Combustion, The Combustion Institute, 1986, pp. 121-128. 
[3] Yu, H.Z., Lee, J.L. and Kung, H.C., "Suppression of Rack Storage Fires by Water," Fire Safety Science - Proceedings of the Fourth International Symposium, International Association for Fire Safety Science, 1994, pp. 901912.

[4] Chan, T.S., Kung, H.C., Yu, H-Z and Brown, W.R., "Experimental Study of Actual Delivered Density for Rack Storage Fires,” Fire Safety Science -Proceedings of the Fourth International Symposium, International Association for Fire Safety Science, 1994, pp.913-924.

[5] Yao, C., "The Development of the ESFR Sprinkler System," Fire Safety Journal, 14: 65-73 (1988).

[6] Kung, H.C., You, H.Z., Brown, W.R., and Vincent, B.G., "Four-tier Array Rack Storage Fire Tests with Fast-response Prototype Sprinklers," Fire Safety Science - Proceedings of the Second International Symposium, Hemisphere, 1988, pp. 633-642.

[7] Kung, H.C., Vincent, B.G., Chan, T.S., Yu, H.Z., and Stavrianidis, P., "Early Suppression Fast Response (ESFR) Sprinkler Protection for $12 \mathrm{~m}$ High Warehouses," Fire Safety Science - Proceedings of the Fifth International Symposium, International Association for Fire Safety Science, 1994, pp. 901912.

[8] “ADD and the Problem of Early Fire Suppression,” ESFR Update Vol. 2, No.1, Factory Mutual Engineering Corp., 1985.

[9] Draft of Approval Standard for Automatic Sprinklers for Fire Protection, Factory Mutual Research Corporation, December, 1997.

[10] Chan, T.S., "Measurements of Water Density and Drop Size Distributions of Selected ESFR Sprinklers," Journal of Fire Protection Engineering, 6: 79-87 (1994). 
